\title{
Maternal near miss events: a retrospective observational study in a tertiary care centre of central India
}

\author{
Ruchita Dadhich, Gita Guin*, Sarika Rawat
}

Department of Obstetrics and Gynecology, N.S.C.B. Medical College, Jabalpur, Madhya Pradesh, India

Received: 13 April 2018

Accepted: 18 April 2018

\section{*Correspondence:}

Dr. Gita Guin,

E-mail: drgita.guin@gmail.com

Copyright: (C) the author(s), publisher and licensee Medip Academy. This is an open-access article distributed under the terms of the Creative Commons Attribution Non-Commercial License, which permits unrestricted non-commercial use, distribution, and reproduction in any medium, provided the original work is properly cited.

\begin{abstract}
Background: Clinically women who have survived complications during pregnancy and childbirth termed as Maternal Near Miss. The major reasons and causes are the same for both Maternal Near Miss and Maternal Death, so review of MNM cases is likely to yield valuable information regarding severe morbidity, which could lead to death of the mother, if not intervened properly and in time. Investigating the instances of severe morbidity may be less threatening to providers because the woman survived.

Methods: It was a retrospective study conducted at the Department of Obstetrics \& Gynaecology NSCB Medical College Jabalpur, Madhya Pradesh, India. Data of maternal death and maternal near miss was collected from the previous records from 1st January 2017 to December 2017 according to WHO 2009 criteria.

Results: Total number of near miss cases was 164 and total number of Maternal Death was 111. Maternal Near Miss incidence ratio was 28.70 per 1000 live births. Maternal Near Miss to Maternal Mortality Ratio was 1.46 and Mortality index was $40.36 \%$. Common cause of Near Miss events was hypertensive disorders of pregnancy - 85 cases $(51.82 \%)$, followed by hemorrhage - 39 cases $(23.78 \%)$. heart disease- 9 cases $(5.48 \%)$ was also common during pregnancy.

Conclusions: In summary, this study shows that besides 111 cases who died, there were another 164 cases who survived due to the prompt diagnosis and treatment received in our set- up However, the overall high incidence of near-miss to maternal mortality (1.46) indicates that a significant proportion of critically ill patient still die of these complications. Maternal near miss reviews will be the best tool for the betterment of community and health care systems.
\end{abstract}

Keywords: Fetal distress, Hypertension in pregnancy, Stillbirths

\section{INTRODUCTION}

The status of health care in a community can be accessed by the maternal mortality rate and maternal near miss. According to World Health Organization (WHO), a maternal death is defined as death of a woman while pregnant or within 42 days of termination of pregnancy, irrespective of the duration and site of the pregnancy, from any cause related to or aggravated by the pregnancy or its management but not from accidental or incidental causes. ${ }^{1}$ Under the Millennium development Goal (MDG) the target for India was to reduce Maternal Mortality Ratio (MMR) by three quarters between 1990 and 2015. As per the latest report of the Registrar General of India, sample registration system (RGI-SRS), Maternal Mortality Ratio (MMR) of India was 167 per 100,000 live births in the period 2011-13. ${ }^{2}$ In terms of numbers, this translates into approximately 44,000 maternal deaths in India $(303,000$ maternal deaths during the same period globally). Despite a one third reduction since 1990, India remains one of the major contributors to maternal deaths in the world. As per the recent sustainable development 
Goals, India is committed to reducing its MMR $<70 /$ lakh live births. ${ }^{3}$ Approximately $65 \%-75 \%$ of the total estimated maternal deaths in India occur in a handful of states- Bihar, Madhya Pradesh, Rajasthan, Uttar Pradesh and Assam. ${ }^{2}$ Our medical college situated in the heart of India which is surrounded by tribal population of Balaghat, Chhindwara, Seoni, Shahdol and Mandla district, they are labeled as tribal districts by Government of Madhya Pradesh. ${ }^{4}$

WHO defined maternal near miss in 2009 as "a woman who nearly died but survived a complication during pregnancy, child birth or within 42 days after termination of pregnancy". ${ }^{1}$ Clinically women who have survived complications during pregnancy and childbirth termed as Maternal Near Miss. Reviews of such cases are considered a less threatening approach to improve maternal health care by the service providers. With this approach, we will be able to identify the delays during the near miss and thereafter take corrective action. Service providers are also happy to report MNM since ultimately the life of the mother is saved. This will enable us to utilize the opportunities to prevent the deaths of mother who might face a similar fate. As Near Miss occurs much more frequent (5-6 times more) than maternal deaths, a more reliable quantitative analysis can provide a comprehensive profile of the health system functioning.

The prevalence of near miss varied between $0.80 \%$ and $8.23 \%$ in studies that used disease-specific criteria. Prevalence was $0.38 \%-1.09 \%$ in the group that use organsystem based criteria. Prevalence was $0.01 \%$ and $2.99 \%$ in studies using management-based criteria. ${ }^{5}$ The rates are higher in low-income and middle-income countries of Asia and Africa.

In Maternal Death Reviews evidences collected by family members and relatives but in Maternal Near Miss events survivor herself narrate all evidences and situations which happened to her starting from personal to health care facility level that landed her in near miss condition so there are less chances of fabricated evidences.

Near miss cases are more common than maternal deaths. The major reasons and causes are the same for both MNM and MDR, so review of MNM cases is likely to yield valuable information regarding severe morbidity, which could lead to death of the mother, if not intervened properly and in time. Investigating the instances of severe morbidity may be less threatening to providers because the woman survived.

One can learn from the women themselves since they survived and are available for interview about the care they received. All near misses should be interpreted as free lessons and opportunities to improve the quality of service provision. Near misses are relatively simpler to analyse and easier to resolve. Broadly, WHO recommends 3 different approaches of selection criteria for identification of maternal near miss cases. They are:

- Disease specific criteria

- Management based criteria

- Organ system dysfunction criteria

Disease specific criteria -Clinical criteria related to specific disease entity like pre- eclampsia, eclampsia, HELLP syndrome, severe haemorrhage, sepsis and uterine rupture. ${ }^{6}$

Intervention based criteria -In most developed countries, admission to intensive care unit or requirement of critical care, have been used to identify near misses. ${ }^{7}$ However the disadvantage of these criteria is the accessibility and availability of intensive care facilities for patients who need them. Other interventions like performance of intrapartum hysterectomy, blood transfusion or caesarean section have been used to identify near misses.

Organ system dysfunction-based criteria -The system is based on the concept that there is sequence of events leading from good health. ${ }^{8}$ The sequence is clinical insult, followed by a Systemic Inflammatory Response (SIR), organ dysfunction, organ failure and finally death. Near misses would be those women with organ dysfunction and organ failures who survive the criteria for defining a near miss and are defined per organ system.

The advantages of this system are that it helps in establishing the pattern of the disease-causing morbidity, comparisons can be made, definition can be standardized and used in many different settings, problem within the health system may be studied and audit can be carried out prospectively.

The disadvantages are that it is dependent on minimum level of care in a country and there must be functioning laboratories for some specific blood tests and basic critical care monitoring must be available.

The practical aspects of WHO criteria includes ${ }^{9}$

\section{Clinical criteria}

Acute cyanosis, gasping, respiratory rate $>40$ or $<6$ breaths /minute, shock, oliguria not responsive to fluids or diuretics, coagulation disorders, total paralysis, loss of consciousness for $\geq 12$ hours, jaundice with pre-eclampsia and unconsciousness with no pulse and heart beats.

\section{Laboratory criteria}

Oxygen saturation $<90 \%$ for $\geq 60$ minutes, $\mathrm{PaO} 2 / \mathrm{FiO} 2$ $<200 \mathrm{~mm} \mathrm{Hg}$, Creatinine $\geq 300 \mathrm{mmol} / \mathrm{L}$ or $\geq 3.5 \mathrm{mg} / \mathrm{dl}$, bilirubin $>100 \mathrm{mmol} / \mathrm{L}$ or $>6 \mathrm{mg} / \mathrm{dl}, \mathrm{pH}<7.1$, lactate $<5$, acute thrombocytopenia $(<50,000$ platelets), loss of consciousness and ketoacidosis and glucose in urine. 


\section{Management criteria}

Continued use of vasoactive drugs, hysterectomy for postpartum haemorrhage or infection, transfusion of $\geq 5$ units of PRBSs, dialysis for acute renal failure, intubation and ventilation for $\geq 60$ minutes and not related to anaesthesia and cardiopulmonary resuscitation.

The objective of this study was to determine the frequency of maternal near miss events, to study the sociodemographic characteristics of the near miss cases and to analyze the causes of near miss events. Following indices were calculated. These are indicators of maternal care.

Maternal near miss incidence ratio per 1000 live births.

Maternal near miss to mortality ratio

Mortality index - (number of maternal death/ number of maternal death+near miss $) \times 100$

\section{METHODS}

The present retrospective study was conducted at the Department of Obstetrics \& Gynaecology NSCB Medical College Jabalpur, Madhya Pradesh, India. All patients according to WHO 2009 inclusion criteria (as mentioned above) for maternal near miss were included in the study. Data was collected from the previous records from 1 st January 2017 to December 2017.

Patient characteristics including age, parity, locality, gestational age at admission, booking status, investigations for anemia, septicemia, eclampsia and for organ system dysfunction/ failure and interventions taken to save the life of the patient were also noted. Maternal Near Miss Incidence Ratio, Maternal Near Miss to Mortality Ratio and Mortality Index was calculated (as mentioned above).

\section{RESULTS}

There were 6028 deliveries and 5713 live births during the study period. Total number of near miss cases was 164 and total number of maternal death was 111. Maternal Near Miss Incidence Ratio obtained in the present study was 28.70 per 1000 live births. Maternal Near Miss to Mortality Ratio was 1.46 and Mortality Index was $40.36 \%$.

Table 1 shows the demographic characteristics of the near miss cases in the present study. The most common age group affected in the near miss cases was 20 to 30 years $(88.41 \%)$. Most of the near miss cases were from rural locality (66.46\%) and didn't get any ANC care (98.78\%). This study concluded that primipara $(61.58 \%)$ were more prone to life threatening complications especially in third trimester $(88.41 \%)$. This picture of study gives an idea about low level of awareness among rural population about their first pregnancy even in last trimester of pregnancy.

Table 1: Demographic characteristics of near miss cases in the present study.

\begin{tabular}{|c|c|c|c|}
\hline \multicolumn{2}{|c|}{ Characteristics } & $\begin{array}{l}\text { Number } \\
\text { (n-164) }\end{array}$ & Percentage \\
\hline \multirow{3}{*}{$\begin{array}{l}\text { Age } \\
\text { (Years) }\end{array}$} & $<20$ & 6 & 3.65 \\
\hline & $21-30$ & 145 & 88.41 \\
\hline & $>30$ & 13 & 7.92 \\
\hline \multirow{2}{*}{ Parity } & Primi & 101 & 61.58 \\
\hline & $>1$ Para & 63 & 38.41 \\
\hline \multirow{2}{*}{$\begin{array}{l}\text { Booking } \\
\text { status }\end{array}$} & Booked & 2 & 1.21 \\
\hline & Unbooked & 162 & 98.78 \\
\hline \multirow{2}{*}{ Locality } & Rural & 109 & 66.46 \\
\hline & Urban & 55 & 33.53 \\
\hline \multirow{3}{*}{$\begin{array}{l}\text { Gestational } \\
\text { age } \\
\text { (Weeks) }\end{array}$} & $\leq 12$ & 11 & 6.70 \\
\hline & $13-28$ & 8 & 4.87 \\
\hline & $29-40$ & 145 & 88.41 \\
\hline
\end{tabular}

Common cause of near miss events in the present study (Table 2) was hypertensive disorders of pregnancy- 85 cases $(51.82 \%)$, followed by hemorrhage- 39 cases $(23.78 \%)$; heart disease - 9 cases $(5.48 \%)$ was also common during pregnancy. Other important causes were Peripartum cardiomyopathy- 3 cases $(1.82 \%)$ and severe anemia (non-hemorrhagic-10 cases $(6.09 \%)$.

Table 2: Causes of near miss events in the present study.

\begin{tabular}{|c|c|c|c|}
\hline \multicolumn{2}{|l|}{ Causes } & \multirow{2}{*}{$\begin{array}{l}\text { Number } \\
(\mathrm{n}-164) \\
30\end{array}$} & \multirow{2}{*}{$\begin{array}{l}\text { Percentage } \\
18.29\end{array}$} \\
\hline Hypertensive & $\begin{array}{l}\text { Severe pre- } \\
\text { eclampsia }\end{array}$ & & \\
\hline & Eclampsia & 55 & 33.53 \\
\hline \multirow{2}{*}{$\begin{array}{l}\text { Early pregnancy } \\
\text { haemorrhage }\end{array}$} & $\begin{array}{l}\text { Ectopic } \\
\text { pregnancy }\end{array}$ & 12 & 7.31 \\
\hline & Abortion & 4 & 2.43 \\
\hline Late pregnancy & $\mathrm{APH}$ & 19 & 11.58 \\
\hline haemorrhage & PPH & 4 & 2.43 \\
\hline Uterine rupture & & 7 & 4.26 \\
\hline Hepatitis & & 5 & 3.04 \\
\hline AFLP & & 1 & 0.60 \\
\hline Heart disease & & 9 & 5.48 \\
\hline PPCM & & 3 & 1.82 \\
\hline Anemia & & 10 & 6.09 \\
\hline Others & & 5 & 3.04 \\
\hline
\end{tabular}

\section{DISCUSSION}

Maternal near miss incidence ratio in the present study is 28.70 per 1000 live births, which is similar to the study conducted in Syria 32.9/1000 live births and Tanzania 23.6/ 1000 live births.10.11 On the other hand it was quite less $17.8 / 1000$ live births in a study by Roopa PS et al from Karnataka and 11.9/1000 live births in a study by Bansal M et al. from Chhattisgarh. ${ }^{12,13}$ Maternal near miss 
incidence ratio was high in studies conducted in Uttar Pradesh 45.2/1000 live births, Assam 42.1/1000 live births, Nepal 40/ 1000 live births and Karachi 50.6/1000 live births. ${ }^{14-17}$

In the study, the near-miss to maternal death ratio is 1.46:1. This indicates that for almost every 2 women who survived life threatening complications, one died. This low ratio may be because our center is a tertiary care center and most cases are moribund at the time of reaching our hospital, a lot of time being lost in transit. This ratio is indicative of the standard of obstetric care that our hospital provides. If this ratio increases over a period of time, it reflects on the improvement achieved in obstetric care. So instead of a single estimation, yearly estimation may help us in improving the care provided.

Present study observed that $145(88.41 \%)$ maternal near miss cases belong to age group of 20-30 years which is comparable to other studies like Yasmin $G$ et al. from Uttar Pradesh-71.30\% maternal near miss cases belong to 20-35-year age group. ${ }^{14}$ Similarly Bansal $\mathrm{M}$ et al. from Chhattisgarh conducted a maternal near miss study and found that $71.78 \%$ cases belong to $<30$ year of age group. ${ }^{13}$

In present study majority of the women suffering near miss events were primipara $(61.58 \%)$. However, in other studies, majority were multipara. ${ }^{13,14}$ This is because of early marriages common in this belt and women entering pregnancy in sub optimal health, often being malnourished and moderately to severely anaemic. Also lack of assertiveness in young women means they are at the mercy of their family members in seeking medical aid. Poor education and low socioeconomic status also means that they are less aware of the pregnancy complications and seek medical help in late stages only. This makes these young women more vulnerable to preeclampsia and eclampsia which alone constituted $51.82 \%$ of all the near miss events. All studies including present study concluded that maternal near miss events were more prevalent in the last trimester and rural population who didn't get any antenatal checkups. ${ }^{13,14}$ This reflects that community is still unaware about pregnancy related complications. This fact is reported by the present study too in which $98.78 \%$ had not taken any antenatal care. With the government laying stress on institutional deliveries which is becoming the norm almost always, the time has come when service providers must be made accountable for the outcome of the pregnancy as well so that the quality of antenatal services can be optimized.

The major cause of near miss cases in our study was hypertensive disorders of pregnancy $(51.82 \%)$. Similarly in India FOGSI conducted a study in 2005-2007 and observed hypertension as the leading cause of maternal death. ${ }^{18}$ Souza et al from Brazil also reported hypertensive disorders as the most commonly associated $(57 \%)$ cause for near miss cases. ${ }^{19}$ Haemorrhage $(23.78 \%)$ was the next determinant for near miss cases, that was mostly because of antepartum haemorrhage (placenta previa and abruptio placentae), FOGSI and Brazilian studies also reported similar findings. ${ }^{18,19}$ Both of these complications can be either picked or atleast be predicted and timely intervention be planned to avoid a near miss event protecting the woman from a lot of short term and long term morbidity like Sheehan's syndrome while also avoiding drainage of valuable resources both in terms of Government, community and personal finances.

In present study $6.09 \%$ cases were because of severe anemia (non-hemorrhagic). It was found that the majority of these critical cases lack proper antenatal care, do not take iron- folic acid tablets either in childhood, adolescence or during pregnancy and are afflicted by food fads and addictions. Repeated childbirth, worm infestation and undiagnosed presence of $\mathrm{Hb} \mathrm{E}$ trait or disease are some other contributory factors leading to severe anemia.

Heart disease was also common amongst pregnant women suffering near miss events. Pregnancy becomes an aggravating factor and may cause life threatening complications like pulmonary hypertension, congestive cardiac failure, arrhythmia or pulmonary edema. 3 cases of peripartum cardiomyopathy were also found in present study; timely diagnosis and treatment salvaged their lives.

\section{CONCLUSION}

In summary, the present study shows that besides 111 cases who died, there were another 164 cases who survived due to the prompt diagnosis and treatment received in our set- up However, the overall high incidence of near-miss to maternal mortality (1.46) indicates that a significant proportion of critically ill patient still die of these complications. Maternal near miss reviews will be the best tool for the betterment of community and health care systems. This will find the gaps in health care right from personal level, community level to health care system levels, this will lead to development and application of corrective measures at all levels and gives positive results for the betterment of our country. So, maternal near miss reviews should be done at periodic interval at all health care facility.

\section{Funding: No funding sources \\ Conflict of interest: None declared \\ Ethical approval: The study was approved by the Institutional Ethics Committee}

\section{REFERENCES}

1. World Health Organization. Evaluating the quality of care for severe pregnancy complications -The WHO near- miss approach for maternal health. Geneva: World Health Organization; 2011.

2. Censusindia.gov.in. (2011). Census of India Website: Office of the Registrar General and Census 
Commissioner, India. [online] Available at: http://www.censusindia.gov.in/ [Accessed 11 Apr. 2018].

3. Sustainable Development Goals (SDGs), Targets, CSS, Interventions, Nodal and other Ministries; http://niti.gov.in/content/SDGs.php.

4. Government of Madhya Pradesh ; Department of Tribal Development ; HRMIS - Human Resource Management Information System.

5. Say L, Pattinson RC, Gülmezoglu AM. WHO systematic review of maternal morbidity and mortality: The prevalence of severe acute maternal morbidity (near miss) Reprod Health. 2004;1:3.

6. Waterstone $\mathrm{W}$, Bewley $\mathrm{S}$, Wolfe $\mathrm{C}$. Incidence and predictors of severe obstetric morbidity :case-control study. BMJ. 2001;322;1089-94.

7. Souza JPD, Duarte G, Basile Filho A. Near miss maternal mortality in developing countries. European Journal Obstetrics and Gynaecology Reprod. 2002;104:80.

8. Mantel GD, Buchmann E, Rees H, Pattinson RC. Severe acute maternal morbidity; a pilot study of a definition for a near miss. Br Journal Obstet Gynaecol. 1998;105:985-90.

9. Say L, Souza JP, Pattinsons RC. Maternal near misstowards standard tool for monitoring quality of health care. Best Practice Clin Obst Gynecol. 2009;23:287-96.

10. Almerie Y, Almerie MQ, Matar HE, Shahrour Y, Chamat AA, Abdulsalam A. Obstetric near-miss and maternal mortality in maternity university hospital, Damascus, Syria: a retrospective study. BMC Pregnancy and Childbirth. 2010;10:65.

11. Nelissen EJT, Mduma E, Ersdal HL, Olsen BE, Roosmalen JJM, Stekelenburg J. Maternal near miss and mortality in a rural referral hospital in northern Tanzania: a cross sectional study. BMC. 2013;13:141.
12. Roopa PS, Verma S, Rai L, Kumar P, Pai MC, Shetty J. Near miss obstetric events and maternal deaths in a tertiary care hospital: an audit. J Pregn.2013:393758

13. Bansal M, Lagoo J, Pujari K. Study of near miss cases in obstetrics and maternal mortality in Bastar, Chhattisgarh, India. Int J Reprod Contracept Obstet Gynecol. 2016;5:620-3.

14. Yasmin G, Najam R, Ghazi S, Lalwani A. Maternal near miss events: a prospective observational study in a tertiary care centre Int J Reprod Contracept Obstet Gynecol. 2016;5:3088-93.

15. Sarma HKD, Sarma HK, Kalita AK. A prospective study of maternal near-miss and maternal mortality cases in FAAMCH, Barpeta; with special reference to its aetiology and management. J Obstet Gynaecol Barpeta. 2014;1:100-6.

16. Shrestha J, Shrestha R, Tuladhar R, Gurung S, Shrestha A. Maternal near miss in a tertiary care teaching hospital. American Journal of Public Health Research. 2015;3:17-22.

17. Mustafa R, Hashmi H. Near-miss obstetrical events and maternal death. J College Physians Surg Pakistan. 2009;19:781-5.

18. Purandare CN. Maternal near miss review: a way forward. J Obstet Gynaecol India. 2013;63:213-5.

19. Souza JPD, Cecatti TG. The near miss maternal morbidity scoring system was tested in a clinical setting in Brazil. J Clin Epidemiol. 2005;58:962-3.

Cite this article as: Dadhich R, Guin G, Rawat S. Maternal near miss events: a retrospective observational study in a tertiary care centre of central India. Int J Reprod Contracept Obstet Gynecol 2018;7:2142-6. 